\title{
Developing Albanian Tourism
}

\section{Lorisa Ylli}

Email: lori.ylli@gmail.com

\section{Doi:10.5901/ajis.2016.v5n3s1p279}

\begin{abstract}
This paper examines the development pattern of Albania's tourism and the effect that this industry will have in the country's economic development. I will attempt to demonstrate that tourism is an indispensable industry in the developing countries like Albania furthermore if it develops through a precise strategy with the government and other institutional support it can contribute to the development of the country. Firstly I will give a general overview of this industry and its capabilities which are relevant in understanding Albania's tourism and its actual situation. In the second part I will describe the strategy that will be implemented by the Albanian government in the tourism sector until 2021 and analyze its overall contribution to this industry.
\end{abstract}

Keywords: Tourism, Economy Growth, Albania

\section{Introduction}

In this project Tourism development will be analyzed and discussed within multiple levels including strategically, its effect on economic development and at the practical level all focusing on the main example Albania.

The main objectives of the project are:

1. Understand tourism development from an industrial and business prospective

2. Detect the challenges faced for the development of this industry

3. Find the effect of government on industrial development

4. Analyze strategies used by the Albanian government (On Tourism)

5. Analyze the effect that tourism development has on economic development

6. Discus the actions which might help the development of Albanian tourism

Motivated by the fact that Albania is a developing country and due to my present study on "Modern Business on Comparative Prospective" specialized on national competitive advantages as well late industrializing countries I thought that tourism development would be one of the major factors that would contribute to Albania's national competitive advantage and as a consequence to future economic development. In order to do this I had to analyze most of the theories on tourism development and at the same time apply a practical case which in this case is Albania. This was what motivated me to undertake this topic.

\subsection{Tourism to Albania}

We can call the actual time as the infancy of the Albanian tourism for the main reason that the country had its first glimpse of international tourism in the $90 \mathrm{~s}$ after the fall of the communist regime that ruled the country for 50 years. Since the 90s it was difficult for the country to establish any kind of industry as in the case of tourism the whole industry was based on internal tourism. Albanian government officials suggest that the development of an internationally competitive industry is possible as $80 \%$ of the coastline is still virgin and untouched by the human hand. Moreover government officials argue that Albania has a strong underlying product with highly saleable potential in the world tourism market.

According to the Albanian government in 2016 the number of foreign visitors reached 1.6 million including ethnic Albanians. The last summer the number of foreign visitors reached 900.000 which indicated that the country was experiencing a tourism "boom" where there was an increase of $35 \%$ of tourism visitors compared with the previous years and from these $92 \%$ were European, 5\% American, 2\% Asian and 1\% other nationalities. According to World Travel \& Tourism council the contribution of tourism in GDP actually is around 3.8\% but from 2016 until 2021 this contribution is estimated to be around $7.5 \%$.

The infrastructure is in constant improvement. In the last 15 years roads highways, international air services were privatized. Moreover the government is implementing always new policies in favor of industrial tourism expansion. 


\subsection{Why tourism?}

Bank of Albania studies indicates tourism is responsible for $6 \%$ of GDP. Tourism income generation annually is between US\$600 million to US\$1 billion in revenue. The governments hope lies in their new project called "Strategy of Albanian Tourism Development" which will be analyzed further on this project.

Other factors that reinforce the importance of this industry in the Albanian region are:

1. The absence of an effective inbound industry serving the foreign tourism market at present.

2. The present historic and archaeological pattern of travel around the country.

3. The presence of a latent inbound operator capacity capable of handling a recovery in the market.

4. Financial resources amongst historical operators to reinvest following pyramid losses are limited and will retard market growth and product development.

Albania has a great development potential when it comes to tourism. Most of the attractions including both cultural and natural have high potential and would have attracted high levels of visitors if they were advertised properly to the right audiences Albania could be positioned similarly as those countries which have high levels of tourism attractions and are geographically small so can build a admired position in the international tourism arena.

However for Albania now is important that the tendencies in the tourism preferences are changing. Culture and adventure as well as ecotourism are considered to be fastest growing markets in the global tourism arena. Their popularity shows that change is accruing. Passive based holidays which started to dominate the market in the 70s are losing market share to theme based holidays which focus in activities of high interest especially adventure and exploration which characterize the Albanian tourism .

Traditional tourism involving "Sun and Beach" still remains one of the largest segments in the international tourism market as it has a normative growth of $2 \%--4 \%$ a year .In the mean time the market on cultural tourism is increasing in some unprecedented levels, its market share is estimated between 60 to 70 million people, with a potential growth of 15\% a year until 2018. Adventures tourism in the other hand is another segment of this market but with a fast growing potential as it has approximately 5 million tourists overall and a growth of $20 \%$ every year. At the end we have natural tourism this segment has an orientation on the exploration of natural resources. In the international tourism market this segment involves $50 \%$ of the overall tourism market and has shown high levels of growth in the last decade .

Our neighbour countries like Greece, Turkey and Croatia are focused on the tourism market of "Sun and Beach" by doing this they have increased the competition in this market heavily. Albania has a unique opportunity to differentiate itself from its neighbours so it separates itself from heavily competitive market with declining potential and low profit margins . Furthermore a tourism which focuses on independent tourists interested in local communities, natural resources and culture has shown to be from 5 to 10 times more profitable in terms of dollars spend from tourists compared to tourism based on "Sun and Beach". What makes Albania a unique attraction is the ability to have a big amount of attractions in a relatively unique aspect and geographically close to each other.

As in terms of its unique market position what it might have started as a necessity it stands now strong and identified in the international tourism market arena. It seems like Albania is situated in ideal position to fulfil the always changing needs of a tourism market based on culture and nature.

\section{Literature Review}

Tourism still remains a term that is subject to diverse interpretations including wide verities of definitions (Richard Sharpley, David J.Telfer, 2002). This reflacts in part the multidisciplinary nature of the topic and in part the abstract nature of the tourism concept (Burns \& Holden, 1995; 5). Despite of all the difficulties tourism can be defined as the activity or process that allegedly acts as catalyst of development (Richard Sharpley, David J.Telfer, 2002). Burkhar and Medlik classify two main groups of tourism definitions (Burkhar \& Medlik, 1981;41-3):

Technical definitions - where they define a tourist as someone that who travels for more than 24 hours outside their normal country of residence

Conceptual definitions - where they argue on the basis of (Nash, 1981) that tourism is simply the activity undertaken by a person at leisure who also travels

Even though this definition tries to explain tourism in its route it has been argued that it takes divers extremes to the main concept. We have to understand that tourism is primarily a social activity (Richard Sharpley, David J.Telfer, 2002). If people wouldn't have neither the desire nor the ability to travel tourism wouldn't exist (Richard Sharpley, David J.Telfer, 2002). Thus tourism is an activity that involves individuals who travel within their own country or internationally 
and interact with other people and places. In short we can say that tourism is a social phenomenon which involves the movement of people to various destinations (Richard Sharpley, David J.Telfer, 2002).

\section{The Methodology and Model}

This research project is based on secondary research (literature review) and primary research (interviews, conversations). As Ghauri and Grounhaug (2000) argue that the main advantage of primary data is that it is useful for a specify project. In this project opinions and beliefs can be analysed through asking the right question to the right people.

\subsection{Primary research}

As Bernard (2000) argued that key informant interviewing works well in a project where the research is dealing with high ranked managers or elite members of community as it is the case on this project where these are chosen on the basis of their characteristic specialised knowledge.

The essence of this project required key informant interviews as the literature on the subject was not enough to analyse and understand in detail the development of Albanian tourism.

My main focus is to understand the ways in which Albanian tourism is going to develop.

Developing an industry is not an easy task and it cannot be done by individuals the only institution that can carry such a big responsibility is the government.

In most of the cases governments construct national tourism strategies and try to implement them in a described period of time. Some of the most tourism oriented economies like Turkey, Greece and Croatia have adopted this views decades ago. So I decided that to better understand Albanian tourism the only possible solution was to approach the right institutions involved with this industry.

In depth interviews more precisely semi structured interviews. These were carried where specific key questions were conduced within a set of skeleton questions. I realized that in order to get the most out of my interviews I had to prepare some close questions as well in order to give more alternatives and gain specific results from my interviews.

Four main interviews were carried with:

Minister of Economic Development, Trade and Entrepreneurship: Prof. Dr. Milva Ekonomi

Director of marketing and promotion in the national tourism agency: Dr. Ardit Collaku

Director of tourism and national culture: Dr. Mensur Bytyci

Director of tourism strategy: Dr. Elton Noli

\section{The findings}

This strategy was developed from the Albanian government in association with the German government. I will try to analyze the most important aspects of this strategy and its contribution to the Albanian tourism development.

\subsection{The strategic position}

\subsubsection{The strategic position of Albania's tourism sector}

According to Dr. Elton Noli the Strategic Director in the Ministry, Albania is a secure tourist destination characterized by a mixture of cultural and natural attractions which are internationally recognized. Within this small geographical location tourism has been managed in a way that all the recourses include here natural and social have been adapted to the needs of the global tourist (customer)". Albania will position itself as an attractive destination for the tourists that require a unique experience which is characterised by highly attractive and authenticable destinations including both cultural and historical. The country will position itself in the tourism arena as a tourism destination that needs to be discovered with the logo "Albania - Yours to explore!"

With its main product the "discovery of Albania" the tourist should be able to absorb and discover the history, nature, archaeology, culture of living, national foods and the population traditions of this amazing country . After leaving the country the tourists would be impressed by the diversity of nature and culture as well the welcoming people of the land of eagles.

According to Dr E.Noli Albania will attempt to specialise and position itself in welcoming unexpected and 
specialised tourism travellers. The main objective here will be the upper middle class of the European, North American population. This demographic segment represents a potential investor that would be prepared to pay for the unique and unprecedented tourism experience. One of the most strongly strategic points in the Albanian tourism will be giving the opportunity to the tourist to visit as much attractions as possible as the geographic position is perfect for these activities In order to keep authenticity the core values and traditions will be caped and enriched in both business terms and individual as well. This will attract more visitors and will be able to enrich more the relationship between the population and the tourists which will eventually lead to more income for the community. In order to keep a constant tourism development the tourists should repeat their visits or advertise the benefits of tourism in terms of mouth to mouth advertising to their friends and relatives so the demand will always be high.

\subsection{Overall strategy}

Strategically the Albanian tourism will develop organically as an authentic destination relying on his rich cultural, historical and natural factors according to most of the Albanian Ministry officials. The best international cultural practises involved in tourism strategies will be studied and worked on so they can adapt cultural tourists. In this section I am going to describe the main tourism products and the preconditions that are needed for the implementation of these strategic tourism products.

The strategic development according to Dr.Noli will be based on three main tourism products namely:

$>$ Sun and Beach

$>$ Special interest

$>$ Business and conference

These tourism products will be supplied to the international tourism market and will be backed up by an advanced marketing, an action plan and a high involvement of human resources which will secure its long term prosperity. Also for the right development of this strategy the government support is crucial. The government should direct and protect all the councils, the private business and the travel agencies in order for this strategy to be successful.

\subsection{Strategic tourism products}

Overall there are a number of tourism products that exists in these industry the Albanian tourism industry will focus their strategy on three main once. Most of the products are characterized by:

$>$ Activities (Business, sports)

$>$ Motivation (Holidays, treatments)

$>$ Price (niche or mass)

Albania is just starting to develop both internal and international tourism these products are essential for its development. They are likely to create a base where all the industry will focus. This strategy suggests that based on these products (which I am going to mention further on)the hole industry will change as all the finance, marketing, HR, infrastructure, government policies, information systems, private businesses will back up the well functioning and development of these tourism products with directions from the ministry of tourism ${ }^{1}$.

\section{4 "Sun and Beach" Tourism (product)}

Albania is well positioned in both the national and international tourism market as a holiday destination with considerable holiday prices based on the assumption (value for money) in the Mediterranean tourism market².

The country has an attractive Riviera in the east side of the Adriatic Sea characterised by beautiful sea sides, clear waters and attractive harbours. The country is the second in Europe after Spain for sunny days approximately 300 out of 360 days a year ${ }^{3}$. The holiday seasons are long based warm weather beautiful atmospheres.

\footnotetext{
1 Toward a Strategy for Culture Tourism and Ecotourism Development.Ministry of Economic Development, Tourism, Trade and Entrepreneurship. September 2016.

2 Toward a Strategy for Culture Tourism and Ecotourism Development.Ministry of Economic Development, Tourism, Trade and Entrepreneurship. September 2016.

${ }^{3}$ www.akt.gov.al
} 
There is high connectivity with the main European cities through most of the methods of transportations including here (sea, air, and land). Relying on the World Tourism Organization "Sun and Beach" tourism until now is one of the markets with the highest demands in the whole world.

Table 1. Tourists attracted form "Sun and Beach" 2016

\begin{tabular}{||l|c|c|c||}
\hline \hline Periods of Time & Short term & Medium term & Long term \\
\hline Home tourists & & & \\
\hline Arrivals & 395.000 & 430.000 & 515.000 \\
\hline Nights stay & 2.834 .000 & 2.825 .000 & 2.875 .000 \\
\hline$\%$ of all arrivals & $54 \%$ & $51 \%$ & $38 \%$ \\
\hline$\%$ of all nights stay & $63 \%$ & $57 \%$ & $45 \%$ \\
\hline
\end{tabular}

Source: Toward a Strategy for Culture Tourism and Ecotourism Development." Ministry of Economic Development, Tourism, Trade and Entrepreneurship. September 2016.

Table 2. Tourists attracted form "Sun and Beach" 2016

\begin{tabular}{||l|c|c|c||}
\hline \hline Periods of Time & Short term & Medium term & Long term \\
\hline All Ethnics & & & \\
\hline Arrivals & 200.000 & 210.000 & 230.000 \\
\hline Nights stay & 1.345 .000 & 1.330 .000 & 1.380 .000 \\
\hline$\%$ of all arrivals & $43 \%$ & $11 \%$ & $42 \%$ \\
\hline$\%$ of all nights stay & $44 \%$ & $77 \%$ & $46 \%$ \\
\hline
\end{tabular}

Source: Toward a Strategy for Culture Tourism and Ecotourism Development." Ministry of Economic Development, Tourism, Trade and Entrepreneurship. September 2016.

\section{5 "Special Interest" Tourism (product)}

Albania has a reputation as one of the few undiscovered countries in Europe in which tourist can still discover unseen secrets relying on wild nature and cultural diversity.

This product is one which has the most potential out of all as most of the international tourist that visit the country in the last years have all targeted this segment of the market ${ }^{4}$.

This graph will show all the main aspects of this product.

Table 3. Tourists attracted form "Special interest" 2016

\begin{tabular}{|l|c|c|c|}
\hline \hline Periods of Time & Short term & Medium term & Long term \\
\hline Foreign tourists & & & \\
\hline Arrivals & 15000 & 69000 & 313000 \\
\hline Nights stay & 80.000 & 400.000 & 1.640 .000 \\
\hline$\%$ of all arrivals & $7 \%$ & $25 \%$ & $58 \%$ \\
\hline$\%$ of all nights stay & $6 \%$ & $23 \%$ & $54 \%$ \\
\hline
\end{tabular}

Source: Toward a Strategy for Culture Tourism and Ecotourism Development." Ministry of Economic Development, Tourism, Trade and Entrepreneurship. September 2016.

\subsection{Business and Conference Tourism (Product)}

This sector specializes on business tourists. Albania has all the conditions to accommodate these types of tourists including here hotels, conference rooms, relaxation atmospheres which make their stay more efficient and reliable. Most of the business centres build in the major cities offer modern business facilities indispensable for business tourists.

${ }^{4}$ Toward a Strategy for Culture Tourism and Ecotourism Development.Ministry of Economic Development, Tourism, Trade and Entrepreneurship. September 2016. 
Through the increased economic potential of the country and near the potential of EU entrance Albania expects to be visited more from this segment of the market. The annual increase of the foreign direct investment makes this market highly attractive ${ }^{5}$.

Table 4. Tourists attracted form "Business and Conference" 2016

\begin{tabular}{||l|c|c|c||}
\hline \hline Periods of Time & Short term & Medium term & Long term \\
\hline Foreign daily $\mathrm{T}$ & 30000 & 40000 & 80000 \\
\hline
\end{tabular}

Source: Toward a Strategy for Culture Tourism and Ecotourism Development." Ministry of Economic Development, Tourism, Trade and Entrepreneurship. September 2016.

\subsection{Pre conditions for the implementation of the strategy}

In order to achieve the objectives that this strategic project is going to address there are some pre conditions that need to be fulfilled.

\subsubsection{Infrastructure}

Infrastructure is one of the biggest obstacles for the development of the tourism in special destinations around Albania. The most important airport Rinas which is located within the capital Tirana and the second biggest city Durres has to reach the international levels. In the future is necessary a second airport in the north as this part of the country is also called the Albanian Riviera and has to absorb most of the flux of visitors. This second airport will be mostly used for the charter flights which in today's standard are the base for development of tourism as an industry.

Indispensable is the organization and development of an efficient rubbish collection and cleaning entity which will help the tourist attractions to be more attractive and clean at the same time.

\subsubsection{Land-law problem resolvance}

The improvement of old and introduction of new lows on property rights and land so the legal systems won't stop the strategic development of this industry

\subsubsection{Tourism laws and regulations on regional and national levels.}

Contemporary formulation of laws is indispensable and regulations on tourism so the governmental organisms can apply and improve the industry.

\subsubsection{Law and order}

Law and order are indispensable and fundamental for the development of tourism as an industry; this applies especially on fields of construction permits and pollution.

\subsubsection{Clear responsibilities on all governmental levels}

Clear description of all responsibilities for all the institutions involved in the tourism arena.

\subsection{Information system}

The effective improvement of the information system so there is clear information on economic levels concerning

${ }_{5}^{5}$ Toward a Strategy for Culture Tourism and Ecotourism Development.Ministry of Economic Development, Tourism, Trade and Entrepreneurship. September 2016. 
Demand and Supply, also it is indispensable that the organization, collection and analysis of data and information is done through the standards of the EU.

Private and public sector involvement Tourism as an industry has to be promoted by the public sector especially in its infancy, but after a certain stage of development the private sector has to be included on this strategy and make its contribution on many levels.

Furthermore the involvement of the private sector is vital as they will be the primary source of financing and investment.

\subsection{This strategy will try to achieve}

Through the achievement of the aims pinpointed in the strategic section which aims at the Albanian tourism's full potential and the development of this sector through sustainable time period on factors such as: culture social, environmental, economical.

This strategy will try to achieve:

$>$ The management of the sector in order to insure the long term economic growth

$>$ The management of tourism industry sub-sectors, in order to approach tourism development through the enrichment of such as natural, social and cultural factors which form the base for the development of this industry.

$>$ Supply the appropriate structure in which profit and investment would reach the highest levels

Eliminate errors and problems within the tourism sector

$>$ Achieve investment from both the private and public sector

$>$ Facilitate the investment and the operation of different businesses in this industry

$>$ Adapt to the overall national economic strategic development

\section{Summary and Conclusions}

This part brings this paper to an end by making some concluding remarks on the study of the Albanian tourism development. Thus the main aim for this dissertation was to analyze describe and discuss the Albanian tourism development it also took a slightly different approach by analysis the effect of this sector on the Albanian economy as well.

As I pointed out in my method and abstract chapters most subjects on this dissertation contribute to the bigger picture of how Albania should develop its tourism sector and how this could affect the country's economy. In a brief summery I gave an overview of the present situation of the actual Albanian tourism industry and the potential that this sector has. Furthermore I took a close look to the main challenges faced by the country and the government in general for the developed of this industry.

Based on several theories on tourism development the main terminology and theories were further analyzed. Literature on the subject as well as the advantages and limitations consisted in previous studies on this manner were analyzed and further explained. Different theorists on tourism development starting from Sinclair who analyzed the economic advantages and disadvantages of tourism development and many others that focused on his views like Eugenio-Martín \& Morales as well as Syriopoulos were mainly concerned with the effects that tourism development had on the economy. Moreover there were other theorists like Liu and Var, Long, Perdue, and Allen and Milne that have contributed to the field of tourism development but in a different prospective. They were concerned with the costs involved by adopting tourism development as an industrialization and development strategy.

Further analysis on the literature detected limitations especially on the methods of development as in the ways in which the countries should carry out tourism development and the actions that need to be taken on order to succeed in this industry. On this basis I have supplied and analyzed the main challenges that the county faces in order to develop the tourism sector. As we sow the challenges were many starting form infrastructure and ending with information management. In order to overcome these challenges the government and other analysts supplied a strategy which I have described in details where tourism products are used in order to develop an industry that it has been said is in its infancy. I in this prospective my study shows that a strategy is not enough and further actions are needed in order to develop the tourism sector. On this basis a detailed discussion was developed in order to understand in detail the actions needed to be taken from the government and the national in general at the same time, in order to develop the tourism sector successfully. This discussion was based on actions that were needed to be taken in any particular fields starting from 
infrastructure and ending in information management so this industry could overcome its infancy stage and affect the country's economy more effectively. At the end we have to understand that this study is highly specialized in only one country and the literature on the field was limited to the government. Hence the actual situation in the Albanian tourism is not bright its future for sure is.

\section{References}

Albania: Guide to its Natural Treasures, ECAT-Tirana, Tirana 2000

Albania: The Bradt Travel Guide (Bradt Travel Guides Ltd), 2005

"Albania: Integrated Coastal Management and clean-up Program: site management framework" SIM-Spa and iMed for World Bank 2005. Albinvest (2016),"Albania Your Investment Destination", Gent Grafic, Tirana

ANIH(2005), http://www.anih.com.al/english/info.asp?idcontent=51\&id=48\&p=1,"Invest in Albania", Visited on 19th of January 2016.

Bernard R (2000), "Social Research Methods:Quality and Quantitative Approaches, Thoudand Oaks, London

Balaguer \& Cantavella-Jorda (2002) J. Balaguer and M. Cantavella-Jorda, Tourism as a long-run economic growth factor: The Spanish case, Applied Economics 34 (2002), pp. 877-884.

Burns, P. and Holden, A. (1995) eds, Tourism: A New Perspective. Harlow

Burkhart, A.J. \& Medlik, S. (1981) Tourism: Past, Present and Future. London: Heineman

Cowen, M. \& Shenton, R. (1996) Doctrines of Development, Routledge, London

Dunn \& Dunn (2002) H. Dunn and L. Dunn, People and tourism: Issues and attitudes in the Jamaican hospitality industry, Arawak Publications, Kingston (2002).

Elliott, J (1998)The Curriculum Experiment. Meeting the Challenge of Social Change, Open University Press: Milton Keynes.

Eugenio-Martín \& Morales (2004) Eugenio-Martín, J. L., \& Morales, N. M. (2004). Tourism and economic growth in Latin American countries: A panel data approach. Social Science Research Network Electronic Paper.

Ghauri and Gronhaug (2002), "Research Methods in Business Studies, Pearson Education, Harlow

Goulet, D. (1992), "Ethics and development: a development ethicist at work", National Geographic Research \& Exploration, Vol. 8 No.2, pp.139-47.

Gursoy \& Rutherford (2004) D. Gursoy and D.G.R. Rutherford, Host attitudes toward tourism: An improved structural model, Annals of Tourism Research 31 (3) (2004), pp. 495-516.

Hazari \& Ng (1993) B.R. Hazari and A. Ng, An analysis of tourists' consumption of non-traded goods and services on the welfare of the domestic consumers, International Review of Economics and Finance 2 (1993), pp. 3-58.

INSTAT (2015), "Economic Indicators of Albania", Tirana Press, Tirana

Jenner \& Smith (1992) Jenner, P., \& Smith, C. (1992). The Tourism industry and the environment. The Economic Intelligence Unit, Special Report, no. 2453, London, UK.

Liu \& Var (1986) J.C. Liu and T. Var, Resident attitudes toward tourism's impact in Hawaii, Annals of Tourism Research 13 (2) (1986), pp. 193-214.

Lonely Planet Guide to Eastern Europe (and web version for Albania, from Lonely Planet, UK) 20011.

Long, Perdue, \& Allen (1990) P.T. Long, R.R. Perdue and L. Allen, Rural resident tourism perceptions and attitudes by community level of tourism, Journal of Travel Research 28 (1990), pp. 3-9.

Milne (1990) S. Milne, The impact of tourism development in small Pacific island states: An Overview, New Zealand Journal of Geography 89 (1990), pp. 16-21

Nash, D. (1981). Tourism as an Anthropological Subject. Current Anthropology, 22 (5): 461-481.

Pearce (1985) D.G. Pearce, Tourism and environmental research: A review, International Journal of Environmental Studies 25 (1985), pp. 247-255.

Sharpley, R. (2002): The Consumption of Tourism.Tourism and Development: Concepts and Issues.Richard Sharpley and David J. Telfer (Der) ss. 300-318. Clevedon, Cahnnel View Publications.

Sinclair (1998) M.T. Sinclair, Tourism and economic development: A survey, The Journal of Development Studies 34 (1998), pp. 1-51

Syriopoulos (1995) T. Syriopoulos, A dynamic model of demand for Mediterranean tourism, International Review of Applied Economics 9 (1995), pp. 318-336.

TTI (Travel \& Tourism Intelligence) Country Reports (Al)

Toward a Strategy for Culture Tourism and Ecotourism Development."Ministry of Economic Development, Tourism, Trade and Entrepreneurship. September 2016

Toward a Strategy for Culture Tourism and Ecotourism Development." Ministry of Economic Development, Tourism, Trade and Entrepreneurship. September 2016.

"Technical Assistance in Developing Nature-Based and Rural Tourism in Albania", unpublished consultant report conducted by World Tourism Organization experts for the United Nations Development Programme -Tirana. October 2005.

Thomas, A. (2000a) 'Meanings and Views of Development', in Allen, T. \& Thomas, A. (eds) Poverty and Development into the Twenty-first Century, Oxford: Oxford University Press.

WTO, Travel and Tourism Analyst, No. 4, 2001 by Travel and Tourism Intelligence

Internet 
Ministry of Economic Development, Tourism, Trade and Entrepreneurship

http://www.ekonomia.gov.al

www.ecotourism.org

http://www.akt.gov.al/en/

www.transporti.gov.al/

http://www.zhvillimiurban.gov.al/

http://www.united-albania.com/albanian-tourism-in-the-news/albanian-tourism-in-the-news.html

http://www.travbuddy.com/Albania-travel-guide-c27 